\title{
Infrasonic monitoring of snow-avalanche activity: what do we know and where do we go from here?
}

\author{
V. Adam , V. Ghritin, M. Rossi, E. van Lancker \\ Laboratory of Electromagnetism and Acoustics (LEMA), Swiss Federal Institute of Technology (EPFL), CH-1015 Lausanne, Switzerland
}

\begin{abstract}
The first recordings of acoustic signals associated with avalanches go back to the 1970s when premonitory low-frequency acoustic emission was observed in the snow cover just before the setting off of natural avalanches (Sommerfeld, 1977; Sommerfeld and Gubler, 1983). Recently, it has been demonstrated that avalanches also produce strong infrasonic vibrations in air during their movement. These infrasonic vibrations propagate great distances and can follow the natural relief. It was then a question of automatically detecting this emission to monitor avalanche activity, with a view to improving forecasting and assisting in the study of certain aspects of avalanche dynamics.

With the double aim of pursuing investigations on the mechanics of the acoustic emission from avalanches and designing an automatic detection system, our laboratory has developed specific instrumentation, the essential link of which is an array of infrasonic microphones associated with a goniometer. Systematic measurements of the infrasonic emissions are being carried out, not only of the natural or released avalanches themselves but of all events with the aim of characterizing the former in relation to "infrasonic noise".
\end{abstract}

\section{INTRODUCTION}

Recent work has demonstrated that snow avalanches have an acoustic emission, particularly strong below $20 \mathrm{~Hz}$, within the infrasonic range (Chritin and Rossi, 1995). These emissions can be detected by an appropriate system including infrasound microphones and signal processing in real time. Thus, one has the possibility of recording automatically avalanche activity over a mountain range: such information could be of prime importance to forecasting systems (Chritin and others, 1996). Since 1995, our laboratory has had at its disposal an experimental system, mainly comprising an infrasound goniometer, allowing localization of an infrasound source (azimuth and elevation are computed in real time) and an acoustical analyser performing a frequency analysis. These data are processed by automatic-recognition procedures to answer the question of whether the detected acoustical event is a snow avalanche or not. One of the most difficult engineering problems encountered was the design of the sensor system and its set-up in very harsh mountainous conditions. This paper presents the assigned system of electro-acoustic transducers designed by our laboratory and its performance related to the detection of infrasonic events such as snow avalanches.

\section{THE EXPERIMENTAL SET-UP}

Our experimental set-up was installed at the Anzère ski resort at an altitude of $2400 \mathrm{~m}$ (Fig. 1). This site is particularly well suited because numerous avalanches are set off there as a precautionary measure, thus allowing their acoustic characteristics to be studied. Furthermore, it is very close to the "La Sionne" experimental site for the study of avalanche dynamics. The processing electronics are installed in a shelter, shielded from bad weather, but the microphones have to be org/10.3189/1998AoG26-1-324-328 Published online by Cambridge University Press located outdoors in what is obviously a very hostile environment.

One of the main difficulties was in fact related to the system of acoustical sensors. Questions of particular concern included, how to protect them, where to install them and how to establish the best conditions for infrasound detection? Furthermore, what were the most suitable microphones?

The first set-up (Rossi and Chritin, 1995) used four outdoor electrostatic-measurement microphones mounted on masts and protected by large shields (Fig. 2). They were in the same horizontal plane and formed a half-cross (Fig. 3).

This set-up had the following disadvantages:

Microphones on masts were exposed to extreme weather conditions: wind, rain, snow, thunder, risk of ice forming and intense sun radiation.

Their masts constituted obstacles on the ski slopes.

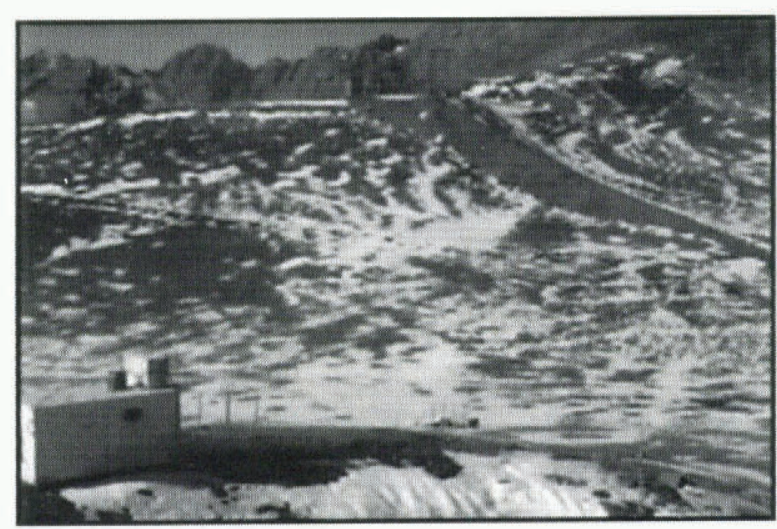

Fig. 1. Experimental site at Anzère ski resort with shelter containing instruments. 


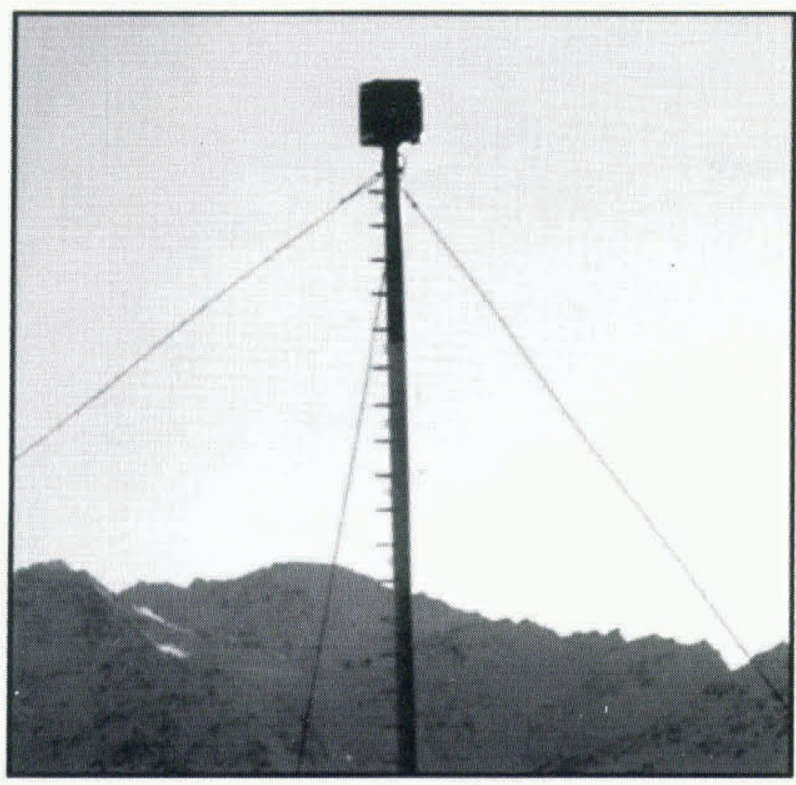

Fig. 2. Electrostatic microphone (ES) protected by shield on top of mast.

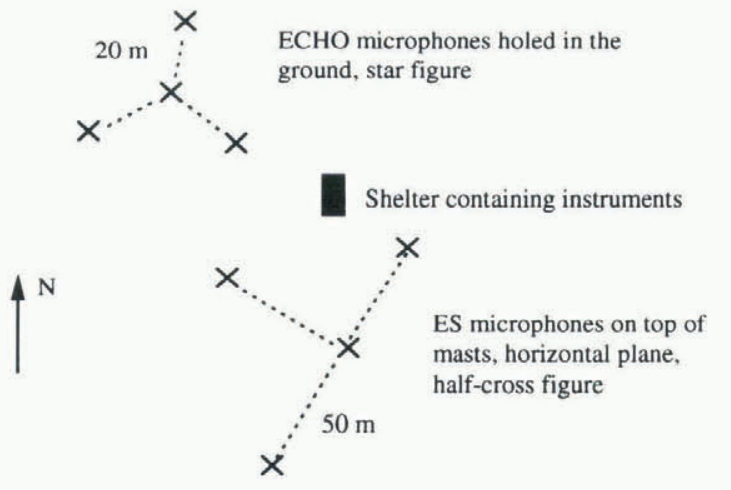

$\times$ Microphones position

\section{Fig. 3. Microphone locations at the experimental site.}

Setting up a mast with a concrete base represented substantial additional cost and environmental impact.

Wind induced noise from the turbulence on the obstacle formed by the microphone and its shield, which added to the noise from the wind on other obstacles; the system was "blinded" by an insignificant amount of wind and its range was thus reduced.

The performance of an outdoor electrostatic measurement microphone is not very well matched for infrasound detection: the low cut-off frequency is too high, the upper one is unnecessarily high and the noise is too high (it follows a $1 / f$ law); a costly high-input impedance pre-amplifier is required.

\section{DESIGN OF A DEDIGATED MICROPHONE}

In 1995, we designed a dedicated microphone for infrasound detection, called ECHO, which was suitable for placing in a pit below the snow cover, with its acoustical-input port protected by a shield. Four ECHOs were installed in November 1995 and are still working perfectly well today.

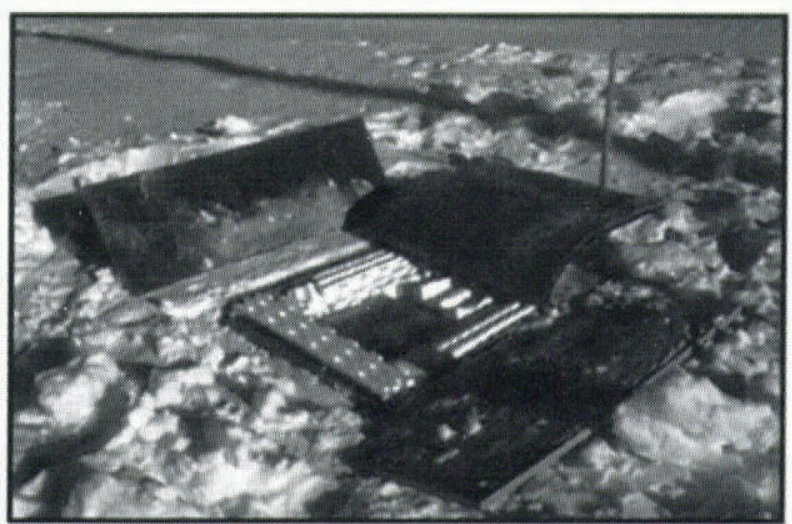

Fig. 4. ECHO microphone installed in the ground at the ex-

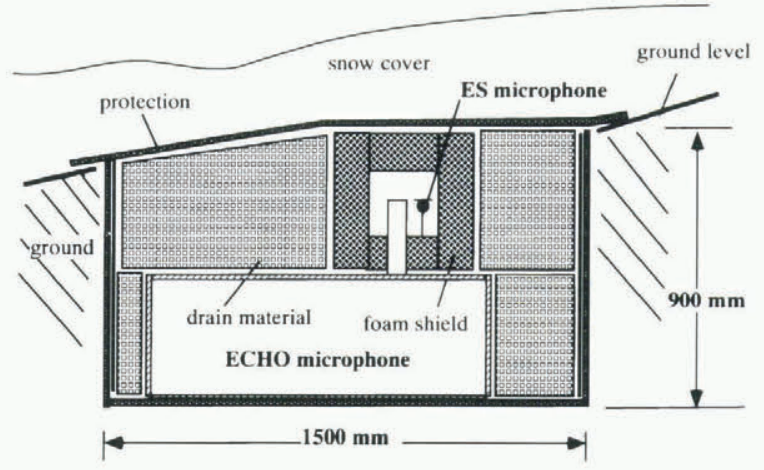

Fig. 5. ECHO microphone scheme.

This microphone was designed to meet the following criteria: low frequency (down to $1.6 \mathrm{~Hz}$ ), low noise (improvement of at least $20 \mathrm{~dB}$ in the signal-to-noise ratio), low cost, simple electronics (low cost), great robustness, low sensitivity to the environment, bulk and size not critical but simple installation without excessive extra costs.

An 18 month investigation was carried out to test these new microphones and to assess their performance. The second experimental set-up was a star (Fig. 3) of four ECHOs in pits below the snow cover, with four supplementary outdoor electrostatic-measurement microphones placed under the shields of the ECHO (Figs 4 and 5). One of these microphones was of a low-noise type, not intended for outdoor use in a hostile environment, so it ceased to function after a few months. The first microphone set-up was maintained in use for comparison purposes.

\section{SENSITIVITY TO WIND NOISE}

Figure 6 shows the outputs of one electrostatic-measurement microphone (abbreviation ES) on a mast and of one ECHO beneath the snow cover, together with the wind speed above the ground. Clearly, the ECHO performs better and its wind-induced noise is lower than that of the ES.

\section{MICROPHONE NOISE}

Figure 7 shows the sound events during a phase of precautionary release of avalanches using explosives dropped from helicopters, as seen by one electrostatic-measurement microphone ES and one ECHO both located in a pit as shown 

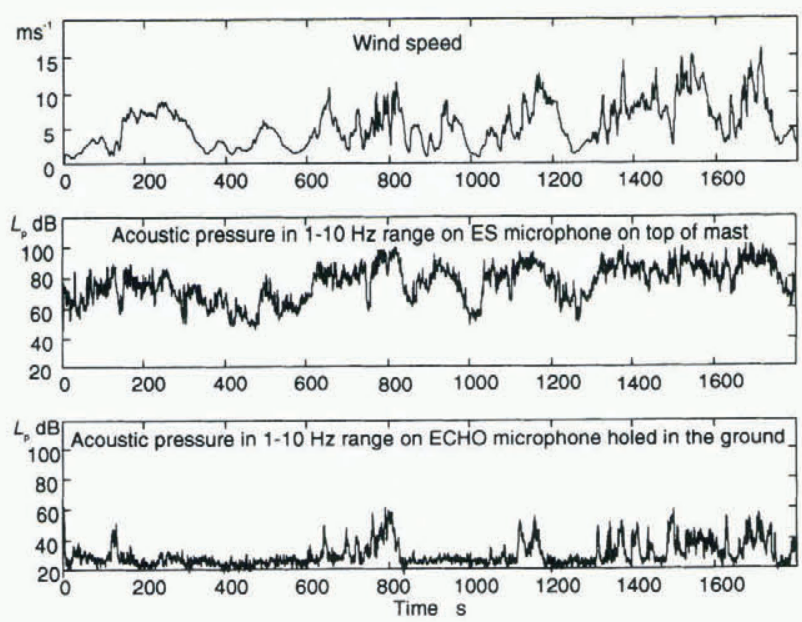

Fig. 6. Comparison of sound pressure levels induced by strong wind on ES microphone (on top of mast) and ECHO microphone (in the ground).
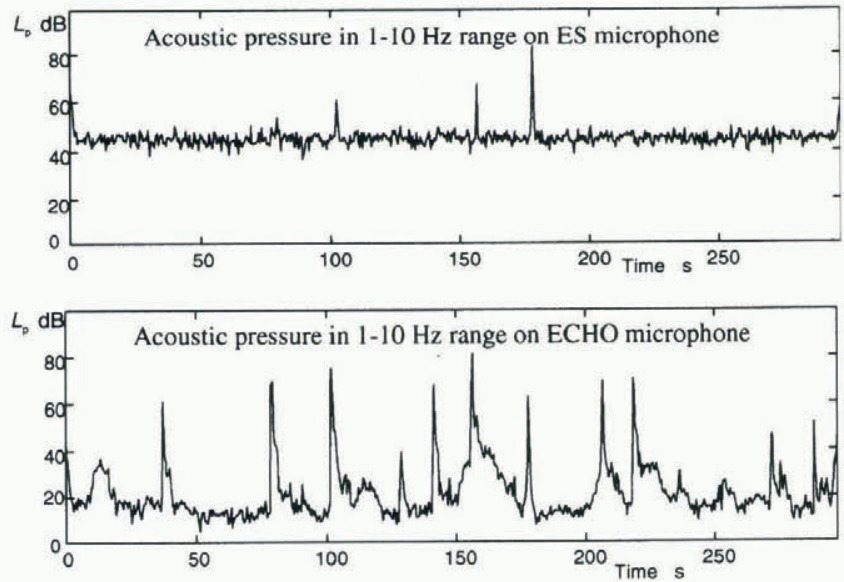

Fig. 7. Comparison of sound pressure levels from ES microphone and ECHO microphone both located in a pit during an artificial release of avalanches. Grey spots show positive releases.

in Figure 4. The output of the ES is very noisy (upper graph); however, the acoustical events are clearly detected by the ECHO (lower graph), particularly the snow slides occurring after the explosions (they were observed visually).

\section{ENVIRONMENTAL INFRASONIC NOISE}

Figure 8 shows the typical ambient noise levels vs time (4 days) as measured by one low-noise electrostatic-measurement microphone (ES) and one ECHO. ES microphone is lying on the ground (no snow cover) under a wind shield and the acoustical-input port of the ECHO is just below ground level. An analysis in one-third octave bands was performed from 1.6 to $16 \mathrm{~Hz}$. A mean value of the wind speed was simultaneously recorded and is represented along the octave-band levels. As shown in Figure 9, in the case of a light wind the ambient noise is practically the same for the two microphones but, in strong wind, the noise is less in the lower part (from 2 to $5 \mathrm{~Hz}$ ) for the ECHO than for the ES.
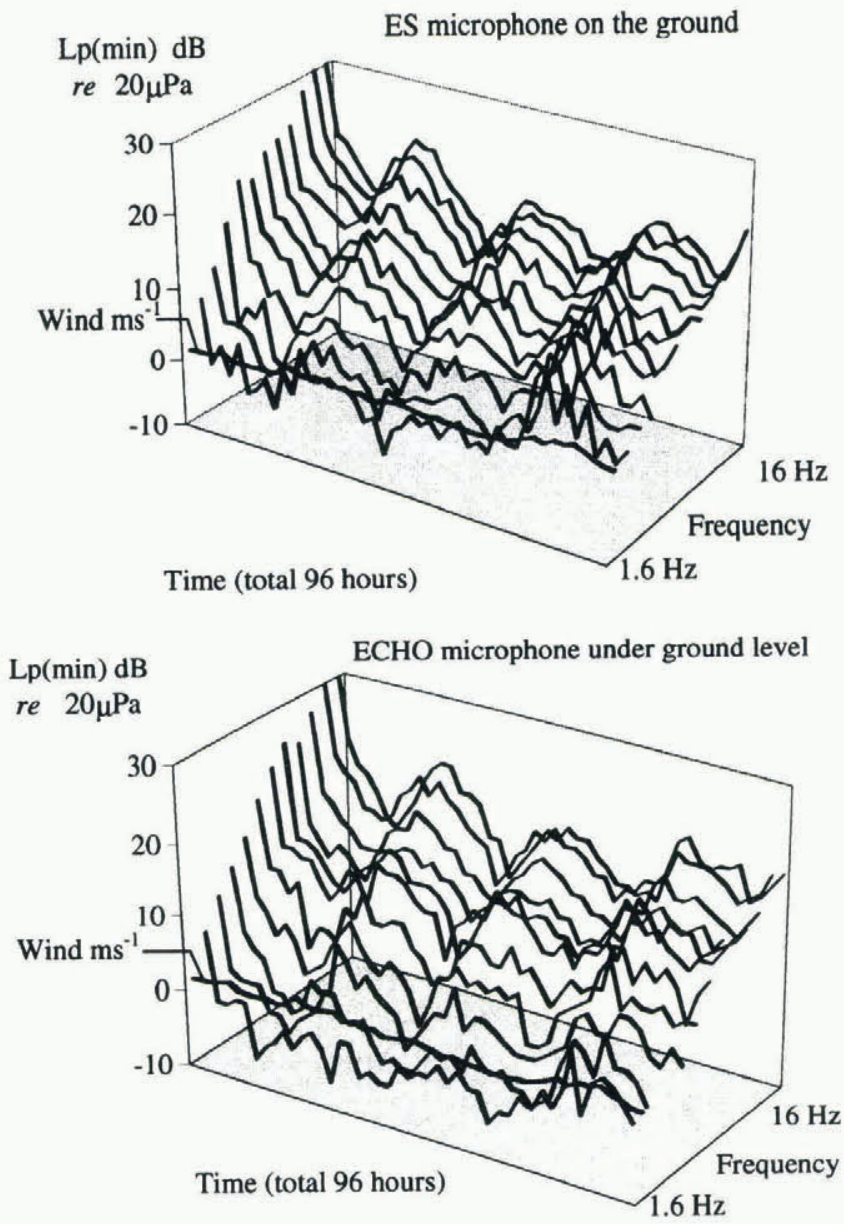

Fig. 8. Four days' continuous recordings of typical ambient noise levels at the experimental site.

\section{SNOW COVER}

Systematic experiments were carried out to determine the effect of snow cover on the acoustical sensors. For this purpose, two ECHOs were installed as shown in Figure 10. The snow cover varied according to the snowfalls. The ECHO above the snow cover was removed between measurement periods. It was sometimes necessary to top up the snow cover which tended to become compacted. Because of this, this more or less porous layer could often become very compacted and once it even contained a layer of ice. Comparison between the signals picked up by both microphones enabled us to determine the effects of the snow cover. Figure 11 shows typical the waveforms of explosions (lower trace: ECHO below snow cover; upper trace: ECHO above snow cover). Overall, in the $1-100 \mathrm{~Hz}$ range, attenuation by a fac-

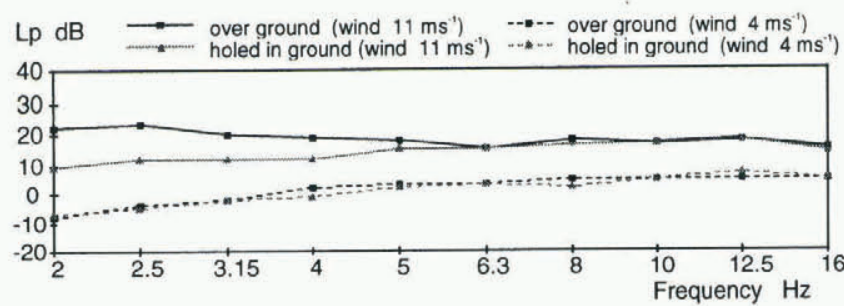

Fig. 9. Comparison of acoustic pressure levels induced by wind at two pick-up locations (microphones above and below ground level without snow). 


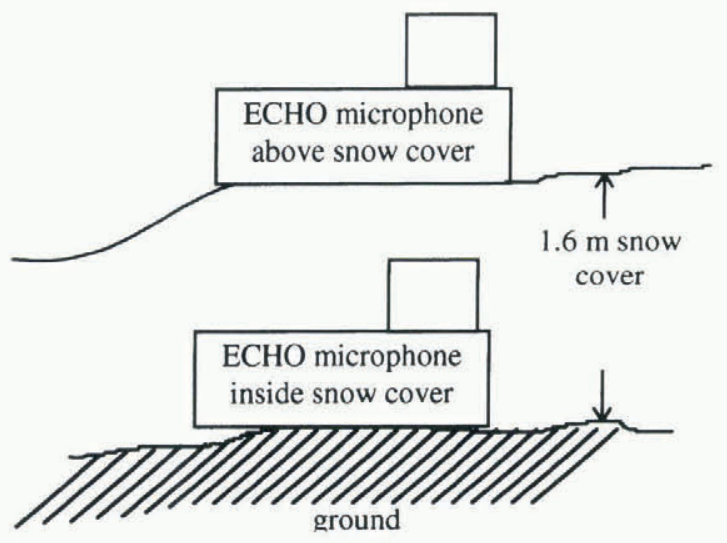

Fig. 10. Experimental sketch to evaluate effects of the snow cover.
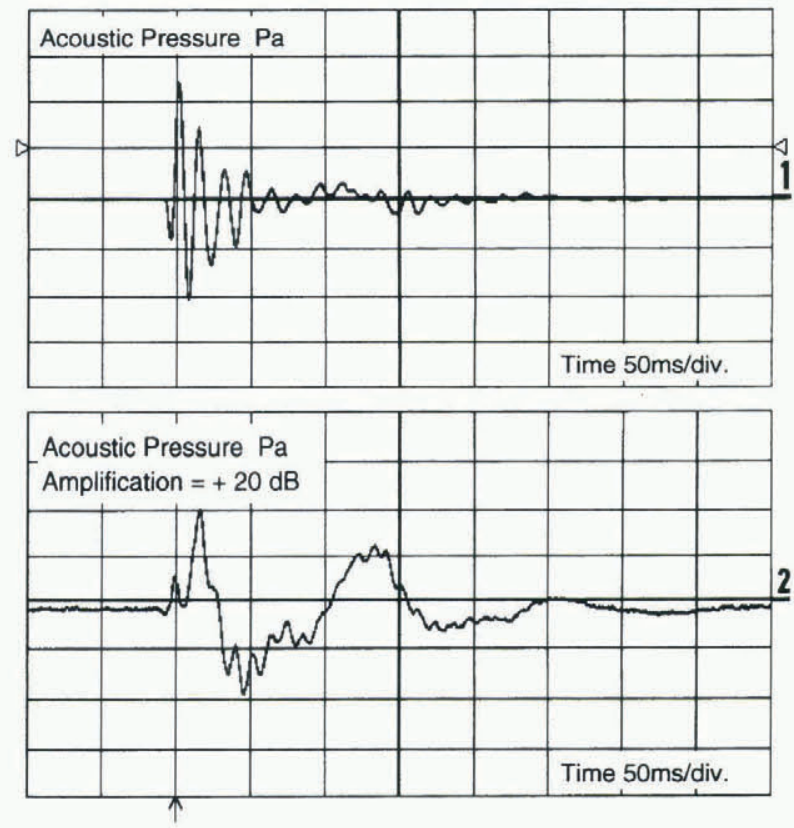

Fig. 11. Typical explosion waveform. Upper trace: pick-up above the snow cover; lower trace: pick-up below the snow cover.

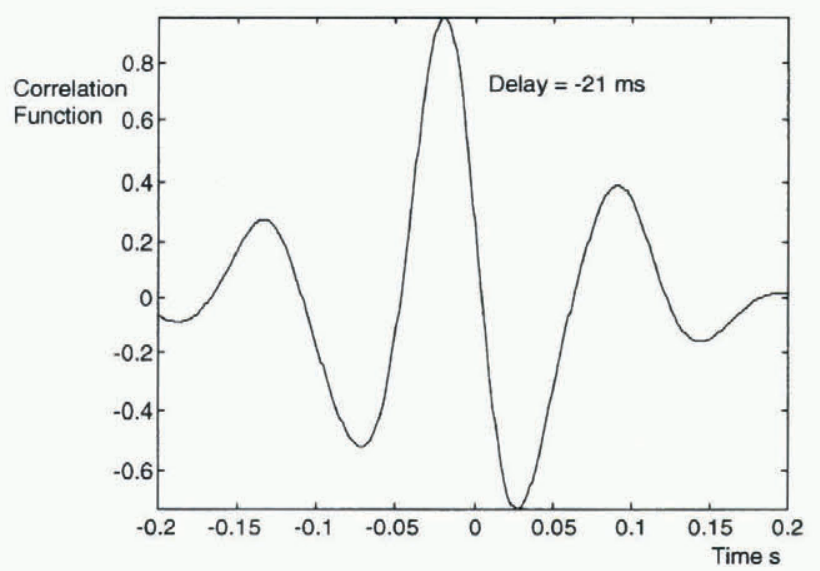

Fig. 12. Typical correlation function between waveforms picked up above and below the snow cover during an explosion.

tor of about 25 is observed, as well as a low-pass filtering effect. Figure 12 shows the correlation between the previous waveforms: a delay of $21 \mathrm{~ms}$ for the signal picked up by ECHO below is observed. This value is virtually indepen-

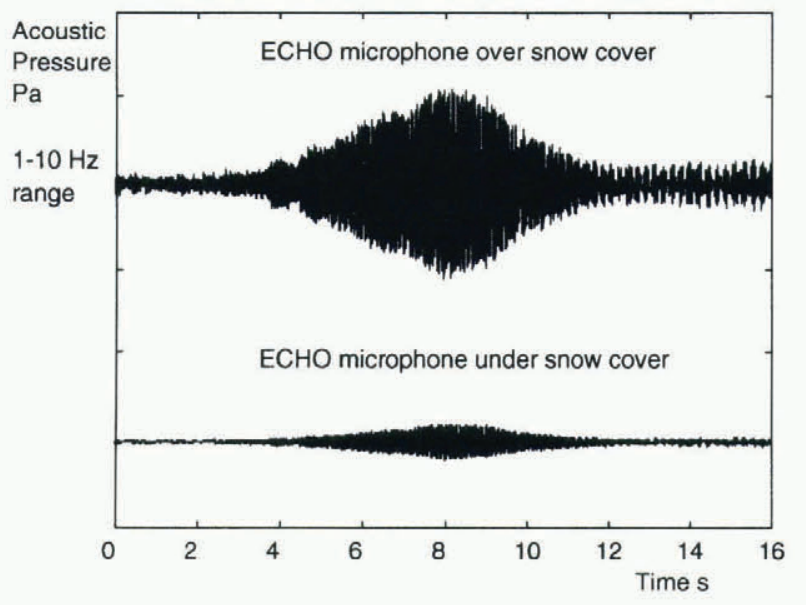

Fig. 13. Typical avalanche acoustic waveforms in $1-10 \mathrm{~Hz}$ range.

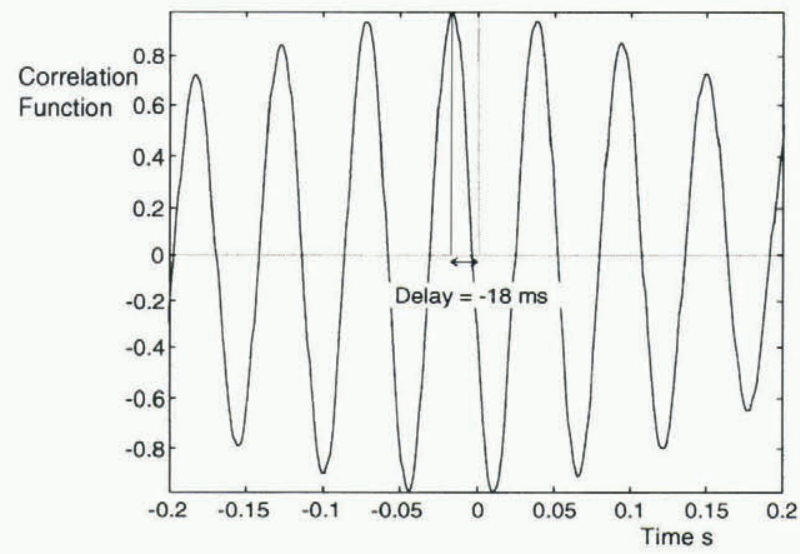

Fig. 14. Typical correlation function between waveforms picked up above and below the snow cover during an avalanche.

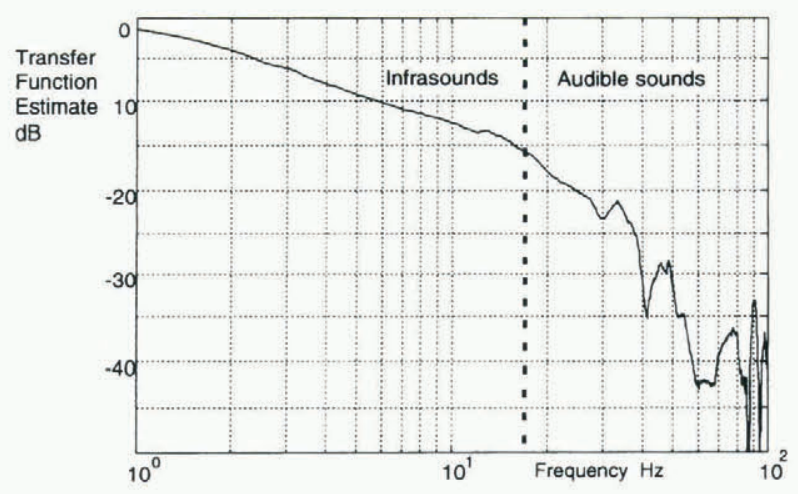

Fig. 15. Measured snow-cover filtering effect.

dent of the distance and direction of location of the explosion (many measurements were made for different locations of the explosions). The snow conditions this year did not allow us to compile sufficient data to correlate this with snow depth.

The observation of acoustic emissions from avalanches also led to the same conclusions. Figure 13 shows the waveforms of an avalanche (lower trace: ECHO below; upper trace: ECHO above the snow cover) and Figure 14 shows their correlation. An estimation of the transfer function between the sound pressures at the acoustical ports of the 


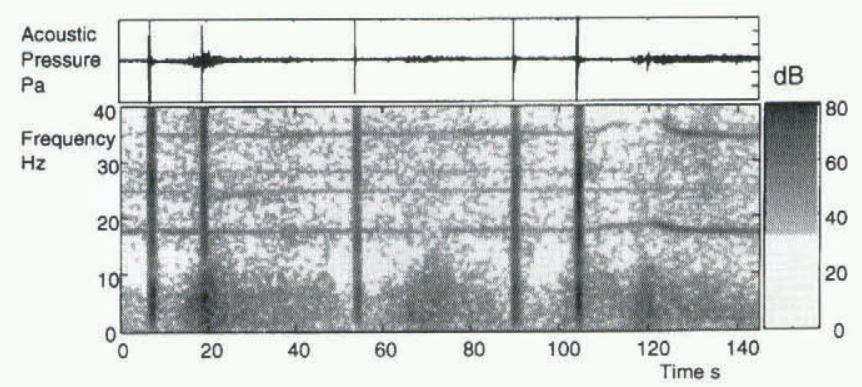

Fig. 16. Waveform (upper) and spectrograph (lower) of a succession of explosions (vertical stripes) and avalanches (grey spots below $10 \mathrm{~Hz}$ ). Horizontal stripes $(17 \mathrm{~Hz}$ and harmonics) indicate the presence of a helicopter.

ECHO above the snow cover and below the snow cover led to the graph shown in Figure 15. In the infrasonic range, in which we are interested for avalanche monitoring, the observed low-pass filtering and attenuation are not excessive.

\section{GONCLUSION}

In conclusion, the ECHO microphone system presents undeniable advantages compared to what was available previously and does indeed fulfil the requirements for which it was designed. To illustrate this, Figure 16 shows the wave- form and the spectrograph of a succession of avalanches picked up by an ECHO below a snow cover of $2 \mathrm{~m}$.

These results are very encouraging, because the development of avalanche-recognition algorithms only makes sense if appropriate detection systems are available. The current state of our research enables us to contemplate, in the short term, installing a pilot system for the automatic detection of avalanches over areas extending up to several square kilometres. The operation of such a pilot system will allow a significant improvement in the forecasting of risk.

\section{REFERENCES}

Chritin, V. and M. Rossi. 1995. Détection acoustique des avalanches: site La Sionne-Anzère, Valais, Suisse. In Sivardière, F., ed. Les apports de la recherche scientifíque à la sécurité neige, glace et avalanche. Actes de Colloque, Chamonix 30 mai-juin 1995. Grenoble, Association Nationale pour l'Étude de la Neige et des Avalanches (ANENA), 261-266.

Chritin, V., M. Rossi and R. Bolognesi. 1996. Snow avalanches: automatic acoustic detection for operational forecasting. Acustica, Acta Acustica, $82(1), \mathrm{S} 173$.

Rossi, M. and V. Chritin. 1995. Microphones pour la détection d'infrasons en montagne. In Journée dëtude sur les transducteurs en milieu hostile. Actes. Paris, Groupe ElectroAcoustique de la Société Française d'Acoustique.

Sommerfeld, R. A. 1977. Preliminary observations of acoustic emissions preceding avalanches. f. Glaciol., 19(81), 399-409.

Sommerfeld, R. A. and H. Gubler. 1983. Snow avalanches and acoustic emissions. Ann. Glaciol., 4, 271-276. 